\title{
Programa Nacional de Alimentação Escolar: uma abordagem das compras institucionais nas microrregiões da Quarta Colônia e Vale do Jaguari do estado do Rio Grande do Sul
}

\author{
National school feeding programme: an institucional purchasing approach at the quarta colonia and vale do jaguari microregions in the rio \\ grande do sul state
}

Tanny Oliveira Lima Bohner, Angela Beatris Araujo da Silva Pereira, Ana Cecília Guedes, Andrea Cristina Dörr

Universidade Federal de Santa Maria

\begin{abstract}
Resumo
O presente trabalho tem como objetivo analisar as compras institucionais dos produtos da agricultura familiar nas microrregiões da Quarta Colônia e do Vale do Jaguari. Para tanto, foram entrevistadas 16 nutricionistas entre os meses de setembro a novembro de 2013, responsáveis técnicas pelo Programa Nacional de Alimentação Escolar (PNAE) nos municípios que compõem estas microrregiões. Os resultados revelam que os municípios pesquisados compram acima dos 30\% previstos em lei, o que evidencia avanços nas compras institucionais da agricultura familiar para a alimentação escolar. Além disso, o programa promove o desenvolvimento socioeconômico do rural e propicia a articulação de produção e consumo de alimentos dinamizando os mercados locais e regionais contribuindo para a melhoria da qualidade da alimentação. Conclui-se que o PNAE é um importante instrumento na promoção da segurança alimentar e na valorização da agricultura familiar.
\end{abstract}

Palavras-chave:

\begin{abstract}
This paper aims to analyze institutional purchases of products from family farming at the Quarta Colônia and Vale do Jaguari microregions. In this regards, 16 nutritionists who are technicians responsible for the National School Feeding Programme (PNAE) in the municipalities that take part in those microregions were interviewed between September and November, 2013. Results show that both microregions purchases over the $30 \%$ prescribed by law, which highlights advances in institutional purchases from family farming for school feeding. Besides, the programme also contributes to the development of the socio-economics of rural communities and foster networking of food production and consumption expanding local and regional markets contributing to improve feeding quality. Thus, it is concluded that PNAE is an important key to promote food security and to add value to products from family farming
\end{abstract}

Keywords: 


\section{INTRODUÇÃO}

No Brasil, o modelo convencional de produção de alimentos caracteriza-se por práticas agrícolas intensivas, com elevada utilização de agrotóxicos e outras tecnologias, o que acarreta consequências sociais e ambientais (MOREIRA e PERES, 2007; PIGNATTI et. al., 2007).

Assim, o estado brasileiro, nos últimos anos, vem discutindo modelos estruturante baseados nos conceitos de Segurança Alimentar e Nutricional (VILLA REAL e SCHNEIDER, 2011). Diante desta perspectiva, busca-se a construção de modelos agroalimentares sustentáveis, capazes de promover a aproximação de pequenos agricultores familiares e consumidores como uma alternativa para a reconexão da cadeia alimentar, aproximando campo e cidade (MALUF, 2007).

Neste sentido, programas alimentares como Programa Nacional de Alimentação Escolar (PNAE) passam a ser vistos como uma política capaz de promover a segurança alimentar dos escolares com alimentos locais, o que possibilita o desenvolvimento socioeconômico das comunidades rurais (VASCONCELOS et al., 2012).

O PNAE é um dos mais antigos programas sociais do Governo Federal na área de alimentação e nutrição. Recentemente, novas diretrizes de execução do Programa Nacional de Alimentação Escolar foram estabelecidas a partir da lei $\mathrm{n}^{\circ} 11.947$ de 16 de junho de 2009. O artigo 14 estabelece que do total dos recursos financeiros repassados pelo Fundo Nacional de Desenvolvimento da Educação (FNDE), no âmbito do PNAE, no mínimo 30\% deverão ser utilizados na aquisição de gêneros alimentícios diretamente da Agricultura Familiar e do Empreendedor Familiar Rural ou de suas organizações (BRASIL, 2009).

De acordo com o FNDE(2013), a per capita repassada pela União a estados e municípios é definida de acordo com a etapa de ensino: creches - $\mathrm{R} \$ 1,00$; pré-escola - $\mathrm{R} \$ 0,50$; escolas indígenas e quilombolas - R \$ 0,60; ensino fundamental, médio e educação de jovens e adultos - $\mathrm{R} \$ 0,30$; ensino integral (Mais Educação) - R\$ 0,90. O valor do repasse é feito com base no censo escolar realizado no ano anterior ao do atendimento. Este valor pode ser complementado pelos governos municipais e estaduais.

As mudanças no PNAE, vieram a somar na construção de mercados institucionais para a agricultura familiar, contribuindo igualmente na promoção da segurança alimentar e nutricional no Brasil (SCHMITT e GRISA, 2013).
A partir desta perspectiva, este artigo pretende refletir sobre a discussão referente às compras institucionais do PNAE da agricultura familiar. Assim, o objetivo desta pesquisa é analisar as compras institucionais da agricultura familiar nas microrregiões da Quarta Colônia e do Vale do Jaguari no estado do Rio Grande do Sul. Estas microrregiões são importantes na economia do Estado, pois destacam-se devido sua participação na agricultura familiar, agroindústria e à pecuária.

Para tanto, buscou-se identificar os produtos adquiridos da agricultura familiar, volumes comprados, recursos gerados para a agricultura, as formas organizativas que se destacam nesta região, assim como as principais dificuldades e potencialidades na gestão desta política na visão dos profissionais, nutricionistas, responsáveis pela operacionalização do PNAE.

\section{MATERIAIS E MÉTODOS}

Para atingir o objetivo proposto pela pesquisa, realizou-se um estudo exploratório e descritivo. De acordo com Gil (2008, p. 27), "as pesquisas exploratórias são desenvolvidas com o objetivo de proporcionar uma visão geral, de tipo aproximativo, acerca de determinado fato".

Já para Marconi e Lakatos (2003) a pesquisa descritiva consiste em uma pesquisa empírica que visa à análise de fatos, fenômenos e avaliação de programas, utilizando artifícios quantitativos para a coleta de dados sobre estas populações. Além disso, tais pesquisas utilizam diversas técnicas como entrevistas, questionários e formulários.

No que se refere à abordagem do problema, este estudo adota o enfoque quantitativo. Segundo Richardson (1999), a análise quantitativa visa garantir a precisão dos dados, evitando distorções de análise e interpretações, o que possibilita uma maior margem de segurança quanto às interferências. Neste sentido, Barbetta (2008) afirma que as medidas quantitativas no geral são mais informativas que as qualitativas.

\section{I Área de estudo}

As microrregiões da Quarta Colônia e do Vale do Jaguari foram selecionadas (Figura 1) devido a critérios de acessibilidade e por que estas duas regiões destacam-se por apresentarem características mais homogêneas em relação às demais microrregiões.

A microrregião da Quarta Colônia está 


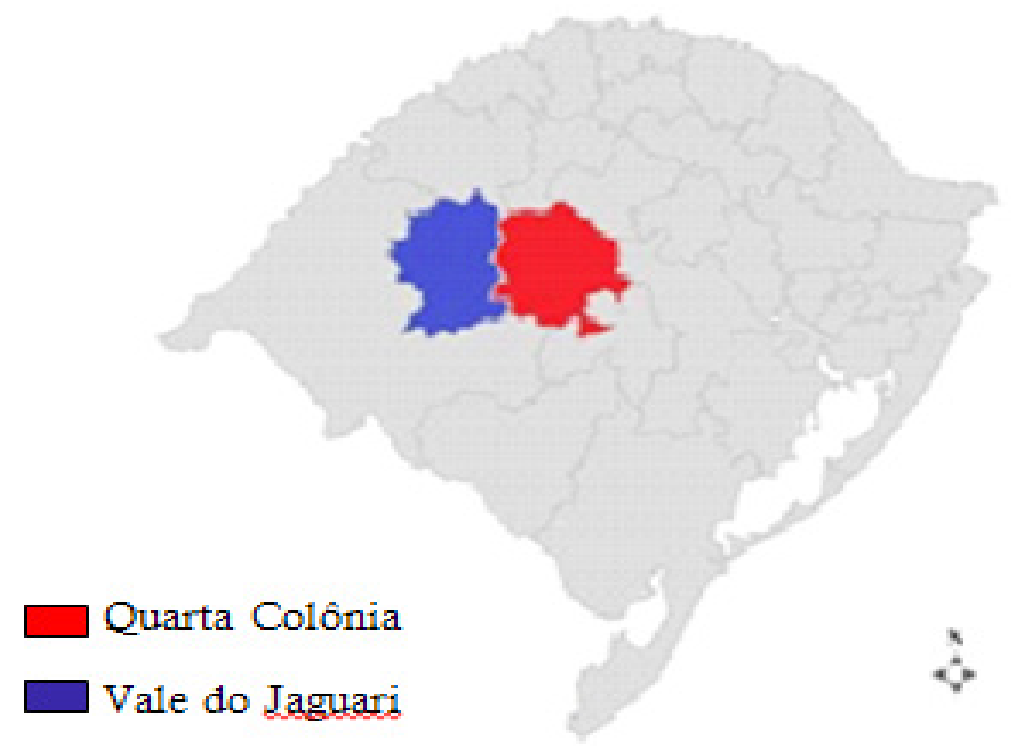

Figura 1: Mapa de localização das microrregiões da Quarta Colônia e Vale do Jaguari. Adaptação própria. Fonte: IBGE, 2013

localizada na Região Central do Rio Grande do Sul, a qual é constituída pelos seguintes municípios: Agudo, Dona Francisca, Faxinal do Soturno, Ivorá, Nova Palma, Pinhal Grande, São João do Polêsine e Silveira Martins. Esta região caracteriza-se pela presença de pequenos municípios sendo que a população urbana e rural são bem distribuídas, sendo que $50,72 \%$ habita o meio rural e $49,28 \%$ o meio urbano dentro de uma área total de 2.899,50 $\mathrm{km}^{2}$, o que corresponde há uma densidade demográfica 20,93 habitantes por $\mathrm{km}^{2}$ (IBGE, 2010).

No que diz respeito à produção agropecuária, a região se caracteriza por pequenas propriedades rurais com predomínio de uma agricultura com uma vasta diversificação de culturas e pelo processamento de produtos de agroindústrias familiares. As atividades produtivas e comerciais que se destacam são: feijão, milho, criação de bovinos e suínos, fumo, arroz e soja (LEONARDI, 2010).

Já a região do Vale do Jaguari, localiza-se geograficamente na Região Centro Ocidental do Rio Grande do Sul, e é composta pelos seguintes municípios: Cacequi, Capão do Cipó, Jaguari, Mata, Nova Esperança do Sul, Santiago, São Francisco de Assis, São Vicente do Sul e Unistalda. Há um forte predomínio da população urbana $76,99 \%$, sobre a população rural $23,01 \%$, que se distribuem em uma área total de $112.681 \mathrm{~km}^{2}$, o que corresponde a uma densidade demográfica 10,4 habitantes por $\mathrm{km}^{2}$ (IBGE, 2010).

A região também possui como base econômica a agropecuária, que contribui com cerca
$30 \%$ da produção. Destaca-se o cultivo do arroz e da soja e a pecuária familiar. Além disso, o setor industrial movimenta apenas 10\% da economia e destaca-se o setor de serviços, em função das atividades relacionadas à administração pública (RIO GRANDE DO SUL, 2012).

\subsection{População}

Para esta pesquisa, optou-se pela utilização do censo, técnica mais indicada quando se trabalha com populações pequenas. Esta pesquisa foi realizada com 16 nutricionistas ${ }^{1}$, responsáveis técnicas pelo programa nas duas microrregiões.

A escolha desta população alvo justificase por sua atuação e responsabilidade técnica na aquisição dos produtos no PNAE. A participação foi voluntária, e os dados foram mantidos confidenciais.

\subsection{Instrumento da pesquisa}

Para coleta dos dados utilizou-se o questionário, o qual apresentou questões abertas e fechadas, com categorias de análise categóricas e contínuas. Gil (2008), destaca que o questionário tem por objetivo o conhecimento de opiniões, crenças, sentimentos, interesses, expectativas e situações vivenciadas.

\footnotetext{
${ }^{1}$ Do um universo de 17 municípios que compõem as regiões da Quarta Colônia e Vale do Jaguari, foram enviados questionário para 16 municípios, ficando fora apenas o município de Silveira Martins que temporariamente não dispõe da nutricionista, responsável técnica pelo programa.
} 
Dessa forma, o questionário abordou aspectos referente aos produtos adquiridos da agricultura familiar, os volumes comprados, os recursos gerados para a agricultura, as formas organizativas que se destacam nesta região, assim como as principais dificuldades e potencialidades na gestão desta política na percepção das nutricionistas responsáveis pela operacionalização do PNAE.

\subsection{Análise dos dados}

Os dados foram tabulados e analisados através de estatística descritiva, através do programa Statistical Package for Social Science (SPSS) versão 22.0. As análises foram feitas por meio de distribuições de frequência, cruzamentos, comparação de médias e correlações de Pearson.

\section{RESULTADOS E DISCUSSAO}

O Programa Nacional de Alimentação Escolar é um dos mais antigos programas sociais na área da alimentação e garante, por meio da transferência de recursos financeiros, a alimentação escolar dos alunos de toda a educação básica ${ }^{6}$ matriculados em escolas públicas e filantrópicas.

Com o advento da Lei n. 11.947, de 16 de junho de 2009, torna-se obrigatória à aquisição de, no mínimo, 30\% dos recursos financeiros repassados pelo PNAE em gêneros alimentícios diretamente da agricultura familiar ou suas organizações. Recentemente, a resolução n. 26 de 17 de junho de 2013, permite o pagamento de um adicional de até $30 \%$ para a compra de alimentos orgânicos, em comparação aos preços dos produtos convencionais.

De acordo com informações do FNDE, o orçamento do PNAE para o ano de 2013 é de 3,5 bilhões de reais. Deste valor, $\mathrm{R} \$ 1,05$ bilhão corresponde aos $30 \%$ destinados às compras diretas da agricultura familiar (BRASIL, 2013).

Dos sete municípios pesquisados na Quarta Colônia, três operam na modalidade de compras municipalizada, ou seja, compram para as escolas municipais e estaduais. Os quatro municípios restantes efetuam suas compras na modalidade não municipalizada, apenas para as escolas municipais. Na Região do Vale do Jaguari, apenas o município de Nova Esperança do Sul opera na modalidade municipalizada (Tabela 1). Os cinco produtos com maior destaque no Vale do Jaguari são leite, laranja, milho verde, alface e mel sachê.
Já na Quarta Colônia, os cinco principais produtos adquiridos são: leite, mel sachê, bebida láctea, laranja e banana prata.

No Vale do Jaguari e na Quarta Colônia, o PNAE atende um universo de 16.287 alunos, distribuídos em 122 escolas. Para este programa, o FNDE repassou R $\$ 768.058,00$ no primeiro semestre de 2013. Deste montante, $\mathrm{R} \$ 345.376,48$ foram utilizados nas compras institucionais da agricultura familiar (Tabela 2).

Na Quarta Colônia, 6.400 alunos de 48 escolas são atendidos pelo PNAE. No primeiro semestre de 2013, o valor repassado pelo FNDE na região foi de $\mathrm{R} \$ 259.628,00$. Deste total, o valor de $\mathrm{R} \$ 128.426,81$ foi utilizado nas compras institucionais da agricultura familiar durante este período, o que representa uma média de $49,47 \%$ na microrregião. O Vale do Jaguari, por abranger um número maior de municípios, atende 9.887 alunos em 74 escolas. Esta microrregião recebeu, no mesmo período, $\mathrm{R} \$ 508.430,00$ e deste total, $\mathrm{R} \$ 216.949,67$ foram destinados para as compras da agricultura familiar, atingindo uma média de $42,67 \%$ nestes municípios (Tabela 2).

Segundo os dados da pesquisa, verifica-se que, em média, a compra institucional da agricultura familiar ultrapassa os $30 \%$ previstos na lei 11.947 de 2009 na microrregião da Quarta Colônia. Ainda de acordo com a Tabela 2, observa-se que os municípios de Ivorá e Nova Palma destacam-se nos gastos com a agricultura familiar, com $84,6 \%$ e $70,77 \%$, respectivamente. Contudo, o município de Dona Francisca apresenta o menor percentual de compras da agricultura familiar, utilizando apenas $27,86 \%$ dos recursos repassados pelo FNDE no primeiro semestre do ano de 2013.

$\mathrm{Na}$ microrregião do Vale do Jaguari, a maioria dos municípios já ultrapassou, no primeiro semestre do ano de 2013 , os $30 \%$ das compras institucionais da agricultura familiar previstos em lei. Destes, Mata destaca-se por já ter usado $80,80 \%$, já Jaguari apresenta o menor percentual $(29,98 \%)$ de emprego do valor repassado pelo FNDE para as compras da agricultura familiar. A microrregião do Vale do Jaguari apresenta um valor total maior gasto com a compra destes produtos, o que pode ser justificado pelo maior número de municípios e de alunos atendidos nestes locais. 
Tabela 1 - Modalidade de compra dos municípios das microrregiões da Quarta Colônia e Vale do Jaguari em 2013.

\begin{tabular}{llccc}
\hline Região & \multicolumn{1}{c}{ Município } & $\begin{array}{c}\text { Número de } \\
\text { alunos }\end{array}$ & $\begin{array}{c}\text { Número de } \\
\text { escolas }\end{array}$ & $\begin{array}{c}\text { Modalidade de } \\
\text { compras }\end{array}$ \\
\hline \multirow{5}{*}{ Quarta Colônia } & Faxinal do Soturno & 1372 & 8 & Municipalizada \\
& Pinhal Grande & 532 & 8 & Não municipalizada \\
& Nova Palma & 1248 & 10 & Não municipalizada \\
& Donado & 1800 & 8 & Não municipalizada \\
& São João do Polesine & 767 & 4 & Municipalizada \\
& Ivorá & 556 & 6 & Municipalizada \\
& Sub Total & 125 & 4 & Não municipalizada \\
\hline \multirow{5}{*}{ Vale do Jaguari } & 6400 & 48 & - \\
& Jaguari & 950 & 6 & Não municipalizada \\
& Unistalda & 200 & 2 & Não municipalizada \\
& Mata & 466 & 4 & Não municipalizada \\
& Capão do Cipó & 350 & 2 & Não municipalizada \\
& Santiago & 1005 & 4 & Municipalizada \\
& São Vicente do Sul & 3397 & 22 & Não municipalizada \\
& Cacequi & 769 & 7 & Não municipalizada \\
& São Francisco & 1100 & 13 & Não municipalizada \\
\cline { 2 - 5 } & Sub Total & 1650 & 14 & Não municipalizada \\
\hline TOTAL & & 9887 & 74 & \\
\hline
\end{tabular}

Fonte: elaborado pelos autores a partir dos dados da pesquisa (2013).

Tabela 2 - Dados financeiros dos municípios das microrregiões de Quarta Colônia e Vale do Jaguari no ano de 2013

\begin{tabular}{|c|c|c|c|c|}
\hline Região & Municípios & $\begin{array}{c}\text { Valor } \\
\text { repassado pelo } \\
\text { FNDE (2013) }\end{array}$ & $\begin{array}{c}\text { Valor gasto com } \\
\text { compras da } \\
\text { agricultura familiar } \\
(2013)\end{array}$ & $\begin{array}{l}\text { Compras da } \\
\text { agricultura } \\
\text { familiar (\%) }\end{array}$ \\
\hline \multirow{9}{*}{$\begin{array}{l}\text { Quarta } \\
\text { Colônia }\end{array}$} & Faxinal do Soturno & $\mathrm{R} \$ 59.844,00$ & $\mathrm{R} \$ 31.132,00$ & $52,02 \%$ \\
\hline & Pinhal Grande & $\mathrm{R} \$ 15.032,00$ & $\mathrm{R} \$ 6.720,00$ & $44,7 \%$ \\
\hline & Nova Palma & $\mathrm{R} \$ 31.728,00$ & $\mathrm{R} \$ 22.455,09$ & $70,77 \%$ \\
\hline & Agudo & $\mathrm{R} \$ 83.976,00$ & $\mathrm{R} \$ 41.804,20$ & $49,78 \%$ \\
\hline & Dona Francisca & $\mathrm{R} \$ 39.976,00$ & $\mathrm{R} \$ 11.139,28$ & $27,86 \%$ \\
\hline & São João do Polêsine & $\mathrm{R} \$ 24.448,00$ & $\mathrm{R} \$ 11.264,50$ & $46,08 \%$ \\
\hline & Ivorá & $\mathrm{R} \$ 4.624,00$ & $\mathrm{R} \$ 3.911,74$ & $84,6 \%$ \\
\hline & Subtotal & $\mathrm{R} \$ 259.628,00$ & $\mathrm{R} \$ 128.426,81$ & $49,47 \%$ \\
\hline & Média & RS $37.089,71$ & $\mathrm{R} \$ 18.346,68$ & \\
\hline \multirow{11}{*}{$\begin{array}{l}\text { Vale do } \\
\text { Jaguari }\end{array}$} & Jaguari & $\mathrm{R} \$ 60.350,00$ & $\mathrm{R} \$ 18.092,25$ & $29,98 \%$ \\
\hline & Unistalda & $\mathrm{R} \$ 7.896,00$ & $\mathrm{R} \$ 3.818,00$ & $48,35 \%$ \\
\hline & Mata & $\mathrm{R} \$ 17.940,00$ & $\mathrm{R} \$ 14.495,95$ & $80,8 \%$ \\
\hline & Capão do Cipó & $\mathrm{R} \$ 24.020,00$ & $\mathrm{R} \$ 11.594,90$ & $48,27 \%$ \\
\hline & Nova esperança do Sul & $\mathrm{R} \$ 33.734,00$ & $\mathrm{R} \$ 11.815,82$ & $35,03 \%$ \\
\hline & Santiago & $\mathrm{R} \$ 216.510,00$ & $\mathrm{R} \$ 78.042,00$ & $36,05 \%$ \\
\hline & São Vicente do Sul & $\mathrm{R} \$ 35.980,00$ & $\mathrm{R} \$ 19.320,35$ & $53,7 \%$ \\
\hline & Cacequi & $\mathrm{R} \$ 28.830,00$ & $\mathrm{R} \$ 29.264,40$ & $101,51 \%$ * \\
\hline & São Francisco & $\mathrm{R} \$ 83.170,00$ & $\mathrm{R} \$ 30.506,00$ & $36,68 \%$ \\
\hline & Subtotal & $\mathrm{R} \$ 508.430,00$ & $\mathrm{R} \$ 216.949,67$ & $42,67 \%$ \\
\hline & Média & $\mathrm{R} \$ 56.492,22$ & $\mathrm{R} \$ 24.105,51$ & \\
\hline TOTAL & & $\mathrm{R} \$ 768.058,00$ & $\mathrm{R} \$ 345.376,48$ & $44,97 \%$ \\
\hline
\end{tabular}

* O município de Cacequi repassa como contrapartida para a alimentação escolar o valor de $\mathrm{R} \$ 68.888,40$

Fonte: elaborado pelos autores a partir dos dados da pesquisa (2013). 
A Tabela 3 apresenta as médias para as potencialidades atribuídas pelas nutricionistas nas duas microrregiões.

Os dados revelam que as as maiores potencialidades para ambas as regiões caracterizam-se pela possibilidade de comercialização direta dos produtos da agricultura familiar, bem como a valorização do meio rural e a melhoria da qualidade da alimentação dos escolares. Contudo, existe alguma diferença em relação aos preços pagos ao agricultor pelos produtos da agricultura familiar entre as duas regiões. As respondentes da região da Quarta Colônia atribuíram uma avaliação maior $(8,42)$ à afirmação "os preços pagos aos agricultores pelo programa são mais interessantes do que os de outros mercados" em comparação às do Vale do Jaguari $(6,77)$, o que reflete a preocupação das nutricionistas da Quarta Colônia quanto à importância do PNAE como promotor do desenvolvimento das comunidades rurais.

Em relação a isto, Leal e Schneider (2011), identificaram a transferência de renda, aproximação entre os agricultores, diversificação da produção e fortalecimento da produção local como sendo as principais potencialidades decorrentes das compras da agricultura familiar para a alimentação escolar.

Observa-se ainda que a média para a variável referente ao intercâmbio entre municípios para a venda dos produtos é maior para a região da Quarta Colônia $(9,28)$ que para a região de Jaguari $(7,33)$. Este resultado indica que a percepção para os municípios da região de Jaguari é de menos abertura comercial entre eles, ou que simplesmente não vêem esse intercâmbio como algo de tal potencialidade. Isto pode ser explicado pela maior proximidade dos municípios da Quarta Colônia.

Tabela 3 - Comparação da avaliação das potencialidades por região

\begin{tabular}{lcccc}
\hline \multirow{2}{*}{\multicolumn{1}{c}{ Avaliação do PNAE }} & \multicolumn{4}{c}{ Região } \\
\cline { 2 - 5 } & Quarta Colônia & Vale do Jaguari \\
\cline { 2 - 5 } & Média & $\begin{array}{c}\text { Desvio } \\
\text { padrão }\end{array}$ & Média & $\begin{array}{c}\text { Desvio } \\
\text { padrão }\end{array}$ \\
\hline O PNAE possibilita a comercialização & 9,57 & 1,13 & 9,33 & 1,41 \\
direta & 8,43 & 1,62 & 6,78 & 3,56 \\
Preços pagos ao agricultor & 9,14 & 1,57 & 8,44 & 1,67 \\
Incentiva a organização dos agricultores & 7,14 & 2,73 & 7,78 & 2,68 \\
Discussão conjunta dos cardápios & 9,29 & 0,95 & 9,11 & 0,93 \\
Melhor qualidade dos produtos e da & 8,43 & 1,62 & 8,67 & 1,41 \\
alimentação & 9,71 & 0,49 & 9,33 & 1,12 \\
Aproxima produtores e consumidores & 9,29 & 1,25 & 7,33 & 3,28 \\
Valoriza o meio rural & & & &
\end{tabular}

Fonte: elaborado pelos autores a partir dos dados da pesquisa (2013).

Tabela 4 - Comparação da avaliação das dificuldades por região

\begin{tabular}{lcccc}
\hline \multirow{2}{*}{\multicolumn{1}{c}{ Avaliação do PNAE }} & \multicolumn{4}{c}{ Região } \\
\cline { 2 - 5 } & \multicolumn{3}{c}{ Quarta Colônia } & \multicolumn{2}{c}{ Vale do Jaguari } \\
\cline { 2 - 5 } & Média & $\begin{array}{c}\text { Desvio } \\
\text { Padrão }\end{array}$ & Média & $\begin{array}{c}\text { Desvio } \\
\text { Padrão }\end{array}$ \\
\hline Burocracia & 5,86 & 2,48 & 5,00 & 3,24 \\
Fragilidade das instituições & 5,57 & 1,62 & 6,56 & 3,47 \\
Falta de produtos legalizados & 7,86 & 2,54 & 7,44 & 3,47 \\
Qualidade dos produtos & 2,57 & 2,07 & 3,22 & 2,49 \\
Falta de habito de comercialização & 6,14 & 2,04 & 6,22 & 2,28 \\
Logística de entrega & 3,71 & 2,14 & 4,78 & 1,56 \\
Falta e regularidade de produção & 5,29 & 2,81 & 5,67 & 2,74 \\
Desinteresse por parte de alguns & 4,71 & 3,20 & 5,22 & 2,73 \\
agricultores & 3,43 & 2,51 & 2,78 & 2,68 \\
Desorganização de algumas prefeituras & 3,29 & 2,93 & 3,56 & 2,60 \\
Resistência das merendeiras & & & &
\end{tabular}

Fonte: elaborado pelos autores a partir dos dados da pesquisa (2013). 
Tabela 5 - Compras institucionais das organizações da agricultura familiar.

\begin{tabular}{clccc}
\hline Região & \multicolumn{1}{c}{ Município } & Grupos & $\begin{array}{c}\text { Cooperativas } \\
\text { (\%) }\end{array}$ & $\begin{array}{c}\text { Associações } \\
\text { (\%) }\end{array}$ \\
\hline \multirow{6}{*}{ Quarta } & Faxinal do Soturno & 78,46 & 21,56 & 0,00 \\
& Pinhal Grande & 100,00 & 0,00 & 0,00 \\
& Nova Palma & 20,00 & 80,00 & 0,00 \\
& Agudo & 23,00 & 77,00 & 0,00 \\
& Dona Francisca & 40,00 & 60,00 & 0,00 \\
& São João do Polêsine & 61,40 & 38,60 & 0,00 \\
& Ivorá & 0,00 & 100,00 & 0,00 \\
\cline { 2 - 5 } & Média & 46,10 & 53,88 & 0,00 \\
\hline \multirow{5}{*}{ Vale do } & Jaguari & 60,00 & 40,00 & 0,00 \\
Jaguari & Unistalda & 60,00 & 0,00 & 0,00 \\
& Mata & 100,00 & 40,00 & 0,00 \\
& Capão do Cipó & 0,00 & 0,00 \\
& Nova esperança do Sul & 100,00 & 0,00 & 0,00 \\
& Santiago & 0,00 & 100,00 & 0,00 \\
& São Vicente do Sul & 100,00 & 0,00 & 0,00 \\
& Cacequi & 40,00 & 0,00 & 60,00 \\
& São Francisco de Assis & 40,00 & 60,00 & 0,00 \\
\cline { 2 - 5 } & Média & 66,60 & 26,60 & 60,00 \\
\hline
\end{tabular}

Fonte: elaborado pelos autores a partir dos dados da pesquisa (2013).

A Tabela 4 apresenta a comparação dos resultados de dificuldades entre as duas microrregiões. Vale ressaltar que na questão das dificuldades, a nota zero equivale a nenhuma dificuldade e a nota dez corresponde à dificuldade máxima.

Verifica-se que as maiores dificuldades para as duas regiões consistem na falta de produtos comercializados e na falta de hábito de comercialização por parte dos agricultores. Entretanto, a avaliação obteve resultados divergentes no que se refere à logística de entrega. Para esta dificuldade, os municípios da microrregião da Quarta Colônia e do Vale do Jaguari atribuíram a nota 3,71 e 4,78, respectivamente. Desta maneira, esta dificuldade adquire maior relevância para esta última região. Isto pode ser explicado porque a Quarta Colônia adquire a maior parte dos produtos de cooperativas, enquanto no Vale do Jaguari predominam as compras de grupos informais (Tabela 5). Neste contexto, Triches e Schneider (2010) destacam a burocracia, legalização sanitária dos produtos, comercialização, logística e organização da produção como as principais dificuldades na operacionalização do PNAE.

A Tabela 5 caracteriza as compras institucionais das organizações da agricultura familiar dos municípios que compõem as microrregiões pesquisadas.
Na microrregião da Quarta Colônia, a aquisição dos alimentos da agricultura familiar em cooperativas contribui, em média, com 53,88\%, seguido dos grupos informais, que representam um valor médio de $53,88 \%$. Em contrapartida, a do Vale do Jaguari adquire, em média, $66,6 \%$ dos produtos em grupos informais e apenas $26,6 \%$ em cooperativas. No que se refere às associações, apenas um município do Vale do Jaguari, Cacequi, realiza suas compras em associações, o que contribui com um valor médio de $6,6 \%$ para as compras da região.

A Tabela 6 apresenta a avaliação das nutricionistas no que se refere à participação dos agricultores no PNAE, melhoria qualidade da alimentação escolar e valor da per capita repassado pelo FNDE às entidades executoras.

Em ambas as microrregiões, a participação dos agricultores foi avaliada de forma positiva, sendo que $57,0 \%$ das nutricionistas da Quarta Colônia e 66,6\% do Vale do Jaguari consideram-na satisfatória. Este resultado também foi observado em relação à melhoria da qualidade da alimentação escolar, apontada como satisfatória por todas as respondentes da Quarta Colônia e 88,8\% do Vale do Jaguari. Quanto ao valor da per capita, 71,42\% das responsáveis pelo programa na Quarta Colônia consideram insuficiente o valor repassado. Já 
Tabela 6 - Avaliação das nutricionistas quanto às melhorias na alimentação através do PNAE

\begin{tabular}{llccc}
\hline Região & Avaliação & $\begin{array}{c}\text { Partic. dos } \\
\text { agricultores } \\
\text { \% (n) }\end{array}$ & $\begin{array}{c}\text { Melhoria da } \\
\text { alimentação } \\
\text { escolar \% (n) }\end{array}$ & $\begin{array}{c}\text { Valor da } \\
\text { per capita } \\
\text { \% (n) }\end{array}$ \\
\hline \multirow{6}{*}{ Quarta } & Muito pouca & $0,00(0)$ & $0,00(0)$ & $28,57(2)$ \\
Colônia & Pouca & $0,00(0)$ & $0,00(0)$ & $71,42(5)$ \\
& Segular & $14,28(1)$ & $0,00(0)$ & $0,00(0)$ \\
& Ótisfatória & $57,14(4)$ & $100,00(7)$ & $0,00(0)$ \\
& Total & $28,57(2)$ & $0,00(0)$ & $0,00(0)$ \\
\hline \multirow{5}{*}{ Vale do } & $100(7)$ & $100(7)$ & $100(7)$ \\
Jaguari & Muito pouca & $11,10(1)$ & $0,00(0)$ & $33,30(3)$ \\
& Pouca & $0,00(0)$ & $0,00(0)$ & $22,20(2)$ \\
& Regular & $22,20(2)$ & $0,00(0)$ & $44,40(4)$ \\
& Satisfatória & $66,60(6)$ & $88,80(8)$ & $0,00(0)$ \\
& Ótima & $0,00(0)$ & $11,10(1)$ & $0,00(0)$ \\
\cline { 2 - 5 } & Total & $100,00(9)$ & $100,00(9)$ & $100,00(9)$ \\
\hline
\end{tabular}

Fonte: elaborado pelos autores a partir dos dados da pesquisa (2013).

no Vale do Jaguari, $44,4 \%$ avaliam a per capita como regular.

No que se refere ao per capita, constata-se que o valor repassado pelo FNDE não é considerado suficiente. No entanto, alguns dos municípios pesquisados já complementam este valor.

O Quadro 1 mostra os coeficientes de correlação linear de Pearson. A análise de correlação de Pearson indica o grau de associação entre determinadas variáveis. Tal coeficiente varia entre $-1 \mathrm{a}+1$, sendo que quanto mais próximos a estes números, maior a força de relação entre as variáveis em questão (AYRES et al., 2007).

Para a análise foram utilizadas e cruzadas todas as variáveis contínuas do questionário. Entretanto, o Quadro 1 apresenta apenas os coeficientes de correlação positiva e negativa próximos a 0,7 . Conforme determina Barbetta (2008), valores acima de 0,7 associam-se a uma forte correlação entre as variáveis.

Os resultados indicam que a valorização do meio rural apresenta uma forte correlação positiva em relação à venda direta dos produtos para as escolas $(0,738)$. Esta valorização correlaciona-se, ainda, ao pagamento de preços mais interessantes do que em outros mercados $(0,816)$, o que demonstra que o programa pode contribuir no desenvolvimento socioeconômico dos municípios.

Os resultados demonstram uma forte correlação $(0,733)$ entre a possibilidade de intercâmbio entre alguns municípios para a venda dos produtos e o incentivo à organização dos agricultores. Isso significa que, quanto maior a possibilidade de intercâmbio e comercialização de produtos fora do seu município, maior será o incentivo para que os produtores se organizem na produção e busca de novos mercados.

Ainda, a possibilidade da discussão conjunta dos cardápios apresenta correlação negativa moderada no que se refere ao desinteresse por parte de alguns agricultores em fornecer $(-0,666)$. Isto por que, quando ocorre a construção conjunta no mapeamento dos produtos da agricultura familiar local, os cardápios respeitam a diversidade e a sazonalidade da produção da agricultura familiar (VASCONCELOS et al., 2012).

Verificou-se ainda uma forte correlação positiva entre o valor em reais utilizado com a compra de alimentos para a alimentação escolar diretamente da agricultura familiar e o valor repassado pelo FNDE para a compra de alimentos para a alimentação escolar $(0,942)$. Ou seja, quanto maior for o valor repassado pelo FNDE, maior será o valor utilizado na compra de alimentos para a alimentação escolar diretamente da agricultura familiar.

Ademais, ressalta-se ainda um coeficiente de Pearson de -0,917 entre o percentual dos produtos da agricultura familiar adquiridos em cooperativas e o percentual de produtos adquiridos em grupos informais. Justifica-se essa correlação fortemente negativa pelo limite de recursos para a alimentação escolar, ou seja, quando se compra nas cooperativas, deixa-se de comprar nos grupos informais. 
Quadro 1. Distribuição dos valores de correlação de Pearson referente às compras institucionais da agricultura familiar nas microrregiões da Quarta Colônia e do Vale do Jaguari

\begin{tabular}{|c|c|c|c|c|c|c|}
\hline $\begin{array}{c}\text { Correlação } \\
\text { de Pearson }\end{array}$ & $\begin{array}{c}\text { Venda } \\
\text { direta }\end{array}$ & $\begin{array}{c}\text { Melhor } \\
\text { preço }\end{array}$ & $\begin{array}{c}\text { Incentivo a } \\
\text { organização } \\
\text { dos } \\
\text { agricultores }\end{array}$ & $\begin{array}{c}\text { Discussão } \\
\text { conjunta do } \\
\text { cardápio }\end{array}$ & $\begin{array}{c}\text { Valor } \\
\text { total }\end{array}$ & $\begin{array}{c}\text { Compra } \\
\text { grupos } \\
\text { informais }\end{array}$ \\
\hline $\begin{array}{c}\text { Valorização } \\
\text { do rural }\end{array}$ & 0,738 & 0,816 & & & & \\
\hline $\begin{array}{c}\text { Intercambio } \\
\text { municípios }\end{array}$ & & & 0,773 & & & \\
\hline $\begin{array}{c}\text { Desinteresse } \\
\text { agricultores }\end{array}$ & & & & $-0,666$ & & \\
\hline Valor gasto & & & & & 0,942 & \\
\hline $\begin{array}{c}\text { Compras } \\
\text { cooperativas }\end{array}$ & & & & & & $-0,917$ \\
\hline
\end{tabular}

Fonte: elaborado pelos autores a partir dos dados da pesquisa (2013).

*Todas as variáveis diferem estatisticamente ao nível de $1 \%$ de significância $(\mathrm{p}<0,01)$.

Verifica-se que ambas as regiões adquirem diversos produtos da agricultura familiar para suprir a alimentação escolar. Ao comparar as quantidades relativas a cada microrregião, observa-se que a Quarta Colônia se destaca por adquirir maior quantidade de alimentos processados (68\%), pães, massas e derivados (62\%), e outros produtos, como farinha de trigo, farinha de milho e óleo de soja (91\%) (Figura 2).
Cumpre ressaltar que a existência de agroindústrias locais favorece a compra de produtos processados. No entanto, alguns destes produtos, assim como farinha de trigo e óleo de soja, não são característicos da região. Tais produtos aumentam o percentual total de compras, contudo a participação dos agricultores locais neste processo pode ficar restrita.

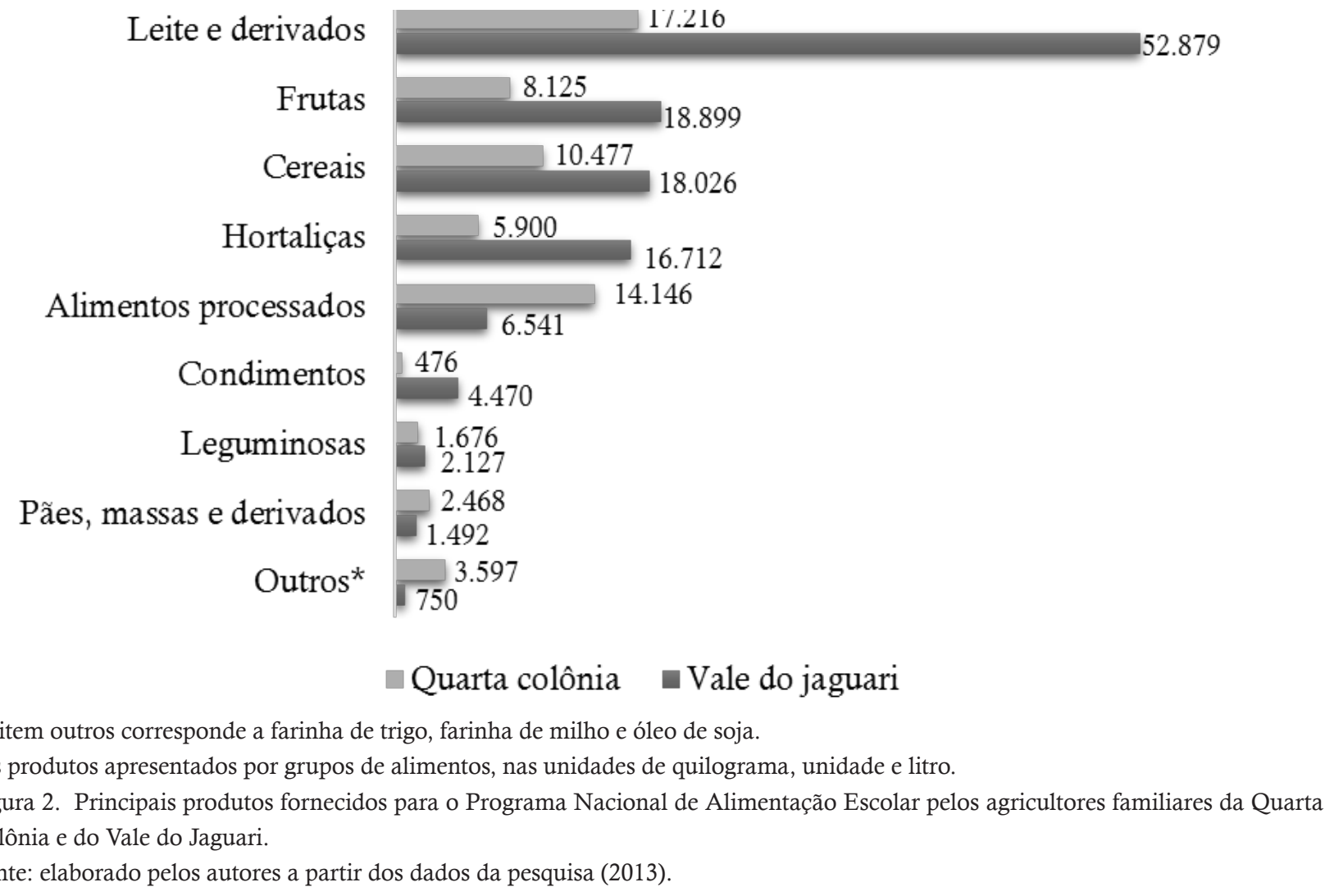


Em comparação, a região do Vale do Jaguari caracteriza-se por comprar uma quantia maior de produtos in natura, hortaliças, leguminosas e frutas, além de um alto percentual de leites e derivados. Isto pode estar relacionado a uma maior participação dos agricultores familiares locais na comercialização dos produtos destinados à alimentação escolar e ao desenvolvimento socioeconômico destes agricultores.

As compras institucionais da alimentação escolar nas microrregionais do Vale do Jaguari e da Quarta Colônia oportunizam a diversificação na produção de alimentos e despertam as famílias rurais para a agroindustrialização de alimentos o que favorece o desenvolvimento local e microrregional. Conforme Grisa (2011), as compras institucionais da alimentação escolar, além da melhoria da alimentação dos escolares, constitui um instrumento de dinamização econômica regional por meio do fortalecimento da agricultura familiar.

\section{CONCLUSÃO}

Conclui-se que as microrregiões da Quarta Colônia e do Vale do Jaguari adquiriram alimentos da agricultura familiar para alimentação escolar, perfazendo um percentual maior que os $30 \%$ recomendados pela Lei 11947/2009. Entretanto, a microrregião do vale do Jaguari adquiriu um percentual menor destes produtos, se comparada à Quarta colônia.

Nesta perspectiva, avanços importantes têm sido observados na operacionalização do programa, o que reflete a melhoria da qualidade da alimentação e garante a segurança alimentar dos escolares. Além disso, tais melhorias promovem ainda o desenvolvimento socioeconômico das comunidades rurais. No entanto, algumas fragilidades, como o número significativo de produtos que não são produzidos localmente e adquiridos em grandes cooperativas, podem representar um entrave à dinamização dos circuitos curtos de mercados.

Assim, os desafios deste programa não se restringem apenas ao cumprimento dos $30 \%$ exigidos pela Lei, mas também ao fortalecimento da agricultura familiar com base sustentáveis. Neste sentido, a resolução ${ }^{\circ} 26$ de 17 de junho de 2013, atua no incentivo de sistemas de produção agroecológica, a partir do pagamento de um diferencial de preço da ordem de $30 \%$ aos produtos orgânicos. Além disso, a ampliação das compras institu- cionais é um dos objetivos da Política Nacional de Agroecologia e Produção Orgânica, publicada no ano de 2012 pelo Governo Federal. Por fim, conclui-se que políticas públicas como o PNAE, além de refletirem o papel do Estado nas políticas de abastecimento e segurança alimentar, beneficiam o desenvolvimento socioeconômico dos locais de atuação, pois valorizam a agricultura familiar, promovem a articulação de produção e consumo de alimentos fortalecendo os mercados locais e regionais.

\section{REFERÊNCIAS}

AYRES, M. at.al.; BioEstat: aplicações estatísticas nas áreas das ciências biológicas e médicas. Belém; Sociedade Civil Mamirauá: MCT-CNPq, 2007.

BARBETTA, P. Estatística aplicada às ciências sociais. 7ed. Florianópolis: Ed. UFSC, 2008.

BRASIL. Ministério da Agricultura e do Abastecimento. Decreto no 6.323, de 27 de dezembro de 2007. Regulamenta a Lei $\mathrm{n}^{\circ} 10.831$, de 23 de dezembro de 2003, que dispõe sobre a agricultura orgânica, e dá outras providências. Brasília; 2007. Disponível em: < http://agricultura.gov.br/ > Acesso em: Dezembro de 2013.

BRASIL. Ministério da Educação. Fundo Nacional de desenvolvimento da educação. Resolução/CD/ FNDE N³8, de 16 de julho de 2009, 2009.

GIL, A. C. Como elaborar projetos de pesquisa. 5. ed. São Paulo: Atlas, 2008.

GRISA, C et.al. O Programa de Aquisição de Alimentos (PAA) em perspectiva: apontamentos e questões para o debate. Retratos de assentamentos, n.13, p.137-170, 2010.

IBGE. Instituto Brasileiro de Geografia e Estatística. Cidades. Brasília, 2013. Disponível em: < http:// cidades.ibge.gov.br/xtras/home.php >. Acesso em: Dezembro de 2013.

LEONARDI, A. et.al. Redes de cooperação em agroindústrias familiares: a casa da Quarta Colônia. $4^{\circ}$ Encontro da Rede de Estudos Rurais; Curitiba 2010.

MALUF, R. S. J. Segurança alimentar e nutricional. Petrópolis: Editora Vozes, 2007. 
MARCONI, M.A., LAKATOS, E.M.; Fundamentos da Metodologia Científica. São Paulo: Atlas, 2003.

PERES, F.; MOREIRA, J.C. Saúde e ambiente em sua relação com o consumo de agrotóxicos em um pólo agrícola do Estado do Rio de Janeiro, Brasil. Cad. Saúde Pública, Rio de Janeiro, 23 Sup 4:S612-S621, 2007

PIGNATTI ,W. A.; MACHADO, J. M. H.; CABRAL, J. F. Acidente rural ampliado: o caso das "chuvas" de agrotóxicos sobre a cidade de Lucas do Rio Verde MT. Rev C S Col, v. 12, n. 1, p. 105-114, 2007

RICHARDSON, R. J. Pesquisa Social: métodos e técnicas. 3 ed. São Paulo: Atlas, 1999.

RIO GRANDE DO SUL. Governo do Estado do Rio Grande do Sul. Mapa de investimentos região funcional 8 - 2012-2015. Porto Alegre, 2012.

SCHMITT, C.; GRISA, C. Agroecologia, mercados e políticas públicas: uma análise a partir dos instrumentos de ação governamental. In: NIEDERLE, P.; ALMEIDA, L.; VEZZANI, F.M. (Org.). Agroecologia: práticas, mercados e políticas para uma nova agricultura. Curitiba: Kairós, 2013.

TRICHES, R.; SCHNEIDER, S. Reconstruindo o "elo perdido": a reconexão da produção e do consumo de alimentos através do programa de alimentação escolar no município de Dois Irmãos (RS). In: Segurança Alimentar e Nutricional, $\mathrm{n}^{\circ} 17$, Campinas, 2010

VASCONCELOS, F.A. G.; et. al. O papel do nutricionista no Programa Nacional de Alimentação Escolar. 2d. Santa Catarina, 2012.

VILLA REAL, L. C.; SCHNEIDER, S. O uso de programas públicos de alimentação na reaproximação do pequeno produtor com o consumidor: $\mathrm{o}$ caso do programa de alimentação escolar. Estudo \& Debate, Lajeado. V.18, n.2, p.57-79, 2011. 